\title{
Household Purchase and Generation of Food Waste in Malaysia (Sri Serdang and Taman Connaught Cheras Kuala Lumpur)
}

Fegalo $\mathrm{K}^{*}$ and Ismail TH

Faculty of Environmental Studies, University Putra Malaysia, 43400 UPM Serdang, Selangor, Malaysia

"Corresponding author: Fegalo K, Faculty of Environmental Studies, University Putra Malaysia, 43400 UPM Serdang, Selangor, Malaysia, Tel: +60 1-800-22-5587; E-mail: fega4lyfe@yahoo.com

Received: July 17, 2017; Accepted: August 10, 2017; Published: August 18, 2017

Copyright: ( $) 2017$ Fegalo K, et al. This is an open-access article distributed under the terms of the Creative Commons Attribution License, which permits unrestricted use, distribution, and reproduction in any medium, provided the original author and source are credited.

\begin{abstract}
Food waste is a problem in developing countries which Malaysia is not exempted, it leads to loss of potential valuable food sources that can be recycled in other forms of energy, waste resources and generated emissions from the food supply chain and challenges associated with disposing organic waste to landfill. This study focused on examining food wastage profile at the household consumer stage in Malaysia. Data collected through questionnaires was given to 311 respondents at Serdang and Cheras area in Malaysia based their leftover food generation and food purchase. Independent sample t test suggest there is no significant difference in the response to not always having leftover food with Serdang $(M=3.12, S D=1.19)$ and Cheras with a sample size of $157(M=3.04, S D=1.31), t$ $(309)=0.598, p=0.55$ (two tailed). The magnitude of the difference in the means (mean difference $=0.85,95 \%$ confidence interval; -0.19 to 0.37 which was very small. there was a significant difference in the score for waste generated in ringgit between Serdang and Cheras Kuala lumpur (Serdang Mean=7.85, SD=3.09) and (cheras Mean=12.12, $S D=5.09)$; $t(257.98)=-4.77$ with a mean difference of $-2.27,95 \%$ confidence interval of -3.208 to -1.333 which is very large. Wastage of food in Cheras area is more than in Serdang Correlation revealed that income, race, food purchase and type or number of house occupant had a positive correlation with the total amount of food waste. Curtailing food waste would increase sustainability and human health in Malaysia thus reducing the stress placed on municipal solid waste management.
\end{abstract}

Keywords: Food; Wastage; Household; Purchase; Malaysia

\section{Introduction}

Food waste is being known for its significance as it exerts a great impact on social, nutrition, and environment. In line with the development of a wider social and environmental awareness, people have grown concerned about the impact of their dietary lifestyles on other individuals and also on the environment as this waste increase the volume of the organic waste stream [1]. Growing concern about hunger, resource conservation, and the environmental and economic costs associated with food waste have raised public awareness of food loss. This has motivated public and private efforts to make better use of available food supplies by implementing nourishing food that would still be a waste. As concern about food waste increases, studies that quantify or estimate food waste have emerged, because these are areas where abundant and inexpensive food supplies are available and waste, rather than reuse [1]. Food consumption alongside food waste generated has drastically expanded and diversified, as previous researchers in developing and developed countries have made attempts to estimate the food waste generated over several decades.

Waste is officially defined in different legal jurisdictions; definitions are particular in line with specific points of arising and are always framed in relation to specific environmental controls. Food waste occurs at different points in the food supply chain, although it is always pointed out at the retail and consumer stages, where outputs of the agricultural system are self-evidently 'food' for human consumption [2]. Food is also a biological material bounded by biological degradation, and different foodstuffs have different nutritional values. Thus, food waste can be defined as wholesome edible material purposed for human consumption, arising at any point in the food supply chain that is instead discarded, lost, degraded or consumed by pests, edible material that is intentionally fed to animals or is a byproduct of food processing diverted away from the human food. Also over nutrition of consumed food per capital and the food needed per capital [2].

From previous research it is estimated that total food losses throughout the food supply chain amount to $50 \%$ of all food that is produced for human consumption. It is therefore clear that food production and utilization processes are highly inefficient [3]. The fast population growth, urbanization, economic levels and increase in the community living standards generates an enormous amount of municipal solid waste (MSW) across the Malaysian municipalities. Historically food consumed and food waste generated has been classified under municipal solid waste generated in Malaysia. Municipal solid waste has been studied since the early 1980s [4]. According to previous research the amount of municipal solid waste generated increased by $2 \%$ annually and is estimated to have reached reach $2.5-3 \%$ due to rapid population and economic growth during the Ninth Malaysia Plan (2006-2010). Based on the census data and Malaysia's current state of waste study, researchers projected that the residential waste generated in 20 studied municipalities increased almost $100 \%$ from 1980 to 1990 due to growing urbanization which reached up to $40 \%$ of population [4]. This study is practically associated with the present situation where the total municipal waste generated in Malaysia increased from 5.91 million tonnes in 2001 to 6.97 million tonnes in 2005. Other researchers concluded that in 2005, municipal solid waste generated was 7.34 million tons and is predicted to increase to 10.9 million tons in 2020 , thus the estimated amount of food waste generated in 2005 is 4.404 million tons and is estimated to 
increase to 6.54 million tons in 2020 [4]. Researchers estimated that leftovers and scraps from food waste are responsible for $60 \%$ of the entire municipal solid waste. Moreover, the average per capita generation rate increased from $0.67 \mathrm{~kg} / \mathrm{capita} /$ day in 2001 to $0.8 \mathrm{~kg} /$ capita/day in 2005 and this amount is expected to increase to double digits in line with the population growth by the year 2020 . This clearly indicates that the quantity of MSW generation of which food waste is included in Malaysia is increasing with time [4].

\section{Food waste generation stages}

Food waste is generally known as all food produced or purchased that is discarded by humans. Food wastage entails all the foods suitable for human consumption that is not being consumed by the population. It includes left over from plate waste, spoiled foods, food given to pets, compost food thrown into garbage disposals or food lost during preparation [5]. However, the left over from consumers is just a small portion of the food waste problem in general. Food loss occurs at various stages in the food supply chain, which includes food transportation, food processing, food storage, distribution, acquisition, retailers, restaurants, and consumption preparation in the kitchen of households.

Wastage at the production stage occurs from natural disasters, insect or predator destruction, and government programs that encourage the production of certain food which sometimes most like leads to over production. During harvestation of food farmers fail to retrieve all food materials on the farm feed which goes to wastage, selective harvesting by farmers, failure or deliberate refusal to harvest farm food products at all due to some economy reasons like low market prices or poor yields [1]. Food waste at the farm level also occurs during storage from spoilage and pest destruction. Inefficient processing methods that remove edible as well as inedible portions of food, and spillage contribute to food processing wastes. In Western nations, much processing waste is comprised of what consumers in these countries consider being inedible portions of food, which includes peels, bones, blood, skins, and eyes and "substandard" items (edible but blemished or small products). Distribution food waste incurs from improper food handling, packaging, and transportation, spoilage, failure of new food items to sell, overstocking, and insufficient stock rotation, Significant food service waste comes from plate scraps, which in some countries are not salvaged because of food safety considerations, and increased portion sizes.

Consumer food waste occurs during food purchase, preparation, and consumption. Improper or lengthen storage are a key cause of consumer food waste [1]. In the process of preparation of food especially in the kitchen, consumers may tend to remove inedible, blemished or damaged portions of foods as well as edible portions such as skins to acquire desired nutritional qualities. Leftover foods being fed to pets, decreases the amount of scraps and rejected food, however it still decreases the availability of foods for humans. The availability of cheap food, particularly in industrialized nations, encourages overbuying and hoarding behaviors that result in waste [1]. Household food waste consists of sources of food and drinks that are consumed within the home include retail and contributions from home grown food and takeaways. In effect, this excludes significant quantities of food and drink eaten 'on-the-go', in the workplace or in catering establishments. Food waste post is referred to as 'food losses' and 'spoilage. Food loss refers to the decrease in food quantity or quality, which makes it unfit for human consumption [2].

\section{Importance of minimizing food waste in households}

In Malaysia, a lot has been done to quantify in general the amount of waste generated, leftover food thrown out by Malaysian household has tremendous financial and environmental consequences. $61 \%$ of food wasted by households could have been eaten, if it had been better managed (i.e., avoidable food waste); with a further $20 \%$ classified as 'possibly avoidable' and only $19 \%$ as unavoidable (i.e., inedible) [3]. The disposal of tonnes of food waste imposes significant cost on community, through waste collection, waste disposal and greenhouse gas emissions related to rotting food. Studies have measured household food wastage as a percentage of total consumed calories, others as a percentage of the total weight of consumed food or as percentage of each of the consumed food items. Food waste aggravates the detrimental environmental effects related with food production and processing, initiating that if there is a reduction in food wasted, the required natural resources like water and land needed for agriculture will be reduced. Therefore, household food waste refers to sources of food and drinks that are consumed within the home, this include food from home grown food and takeaways.

The high amount of food waste generated is the main cause to most issues related to landfills such as foul odor, toxic leachate, emission of greenhouse gases and vermin infestation [6]. An enormous portion of food waste consists of food that could be suitable for human consumption. Previous research reveals that $61 \%$ of edible is food wasted by households, if it is managed properly, with a $20 \%$ of the food classified as 'possibly avoidable' and $19 \%$ as unavoidable (i.e., inedible food) In the United Kingdom. This states that a large amount of food, much of which could potentially feed almost 1 billion people worldwide $(13 \%$ of the global population) classified as undernourished, is going to waste, thereby elevating problems of hunger and food insecurity, particularly in poorer countries [6]. Reducing the amount of food wasted after production could therefore play an important role in meeting the challenge of feeding population that is being faced with hunger. In addition to this, the disposal of inedible food represents the loss of potentially valued resources that could be incorporated into other processes, such as composting or the production of biogas or animal feed. Wasted food means that the resources used for producing the food are wasted [6]. For example, the agricultural sector consumes a substantial proportion of global water supplies. By reducing food losses and waste, such that less food would need to be produced, usage of agricultural water could therefore be reduced. Greenhouse gasses that are released during the production (especially meat production), transport, processing and storage of food, contribute to climate change. Emissions released during the production and processing of food ends up being discarded can be considered as wasted emissions [6]. Also, disposal of food waste to landfill is also a prominent contributor to greenhouse gas emissions, and leachate. Disposal of organic waste which includes food waste and garden waste to landfill is prohibited in many countries, where the government lays emphases on the need to reduce disposing organic waste to landfill which contributes to greenhouse gas emissions [3]. Landfill gas, generated due to the decomposition of organic waste, is mainly made up of methane (40-70\% by dry volume) (European Commission, 2000), which has a 20-25 times stronger warming effect than $\mathrm{CO}_{2}$ on a molecular basis Methane contributes about $18 \%$ towards total global warming, or 500 million tonnes per year, of which 40-75 million tonnes (8-15\%) is attributed to emissions from landfills. The disposal of organic waste (including food waste) to landfill is therefore becoming a significant contributor to global warming [3]. Hence this study will focus on examining food purchase profile at the 
Page 3 of 8

household consumer stage in Malaysia. Specifically, it will focus on determining if there is any evidence of food waste and the factors that are responsible for this wastage. The study will also raise awareness on the main sources of food loss and value of food that households are throwing away.

\section{Study Area and Methods}

\section{Participants and location}

Data was collected through questionnaires given to the project participants at the selected project site, which are Sri Serdang and Cheras area in Malaysia. The questionnaire was constructed based on the review of literature.

Questions were chosen to get information about various households on their leftover food waste generation and food purchase [7]. All the respondents were approached at the selected areas based on willingness to participate in the survey. A total of 311 respondents gave their responses. The respondents came from various backgrounds and ethnicity [5].

\section{Data collection and analysis}

Data collected after carrying out the survey, questions consist of 18 items with five major part which includes, demographics of respondent, food shopping profile, food consumption leftover food pattern, food waste pattern per week and reasons for food waste questions where measured with likert scales and ordered in the progression of higher numbers represent level of agreement. The main characteristic of the likert scale is that the categories possess an ordered relationship to each other. This type of scale permits the measurement of degrees of difference, but not the specific amount of difference. This means that data can be interpreted in terms of differences in the distance along the scale. An example of the ordinal scales used in the questionnaire for this research is as follows: [Strongly disagree-1, disagree-2, agree slightly-3, agree-4, strongly agree-5] [8]. Different test, which includes independent sample $t$ test, and linear regression test were used with the statistical package for social science software.

\section{Results and Discussion}

\section{Demographics of respondents on the survey}

This survey focused on residents at Cheras Taman Connaught and Serdang Selangor Malaysia as shown in Table 1. 157 samples were collected from Cheras while 154 samples were collected from Serdang, $62.7 \%$ were females and $37.3 \%$ were males. Races of Malay, Chinese, Indian and other nationalities resident in these areas, with more samples of employed respondents than unemployed respondents. The sample also consist of households of family with child/children at $26 \%$, family of adults at $35.0 \%$, shared non-related males and females at $25 \%$, single occupancy at $14.2 \%$ all and highest income range of RM1500 to RM3000.

\begin{tabular}{|l|l|l|l|}
\hline \multicolumn{2}{|l|}{} & Percentage \% & \multirow{2}{*}{ Mean (SD) } \\
\hline \multirow{2}{*}{ Gender } & Male & 37.3 & \multirow{2}{*}{$1.63(0.48)$} \\
\cline { 2 - 4 } & Female & 62.7 & \\
\hline
\end{tabular}

\begin{tabular}{|c|c|c|c|}
\hline \multirow{5}{*}{ Age group } & $<20$ & 0.3 & \multirow{5}{*}{$3.42(0.99)$} \\
\hline & $20-30$ & 20.3 & \\
\hline & $30-40$ & 31.8 & \\
\hline & $40-50$ & 32.5 & \\
\hline & $>50$ & 15.1 & \\
\hline \multirow{4}{*}{ Race } & Malay & 33.8 & \multirow{4}{*}{$2.12(1.01)$} \\
\hline & Chinese & 32.8 & \\
\hline & Indian & 21.5 & \\
\hline & others & 11.9 & \\
\hline \multirow{2}{*}{ Residence } & Serdang & 49.5 & \multirow{2}{*}{$1.50(0.50)$} \\
\hline & cheras & 50.5 & \\
\hline \multirow{2}{*}{ Job status } & Employed & 85.5 & \multirow{2}{*}{$1.14(0.35)$} \\
\hline & unemployed & 14.5 & \\
\hline \multirow{4}{*}{ Income } & $<1500$ & 4.5 & \multirow{4}{*}{$2.79(0.93)$} \\
\hline & $1500-3000$ & 41.2 & \\
\hline & $3000-5000$ & 23.2 & \\
\hline & $>5000$ & 29.6 & \\
\hline \multirow{5}{*}{ Resident type } & Bungalow & 10 & \multirow{5}{*}{$3.23(1.14)$} \\
\hline & Single story link & 19 & \\
\hline & Double story link & 17 & \\
\hline & Apartment/condo & 46.6 & \\
\hline & others & 7.4 & \\
\hline \multirow{5}{*}{$\begin{array}{l}\text { Academic } \\
\text { qualification }\end{array}$} & Diploma & 4.5 & \multirow{5}{*}{$2.48(0.83)$} \\
\hline & Degree & 57.6 & \\
\hline & Masters & 26.4 & \\
\hline & $\mathrm{PhD}$ & 8.7 & \\
\hline & others & 2.9 & \\
\hline \multirow{4}{*}{ House occupants } & Single occupancy & 14.2 & \multirow{4}{*}{$5.13(1.91)$} \\
\hline & $\begin{array}{l}\text { Shared and non- } \\
\text { related }\end{array}$ & 25 & \\
\hline & Family only adults & 34.7 & \\
\hline & $\begin{array}{l}\text { Family with } \\
\text { children }\end{array}$ & 26 & \\
\hline
\end{tabular}

Table 1: Demographics of Respondents.

\section{Food shopping profile}

Table 2 below shows the food shopping profile of the respondents most of the respondents shopped for their food mostly at supermarket with the highest mean of 4.16 and a standard deviation of 1.08 also the mean of people who did their food shopping online (internet) was observed to be the least with a mean of 1.53 . The average number of 
sample do their main food shopping on one big weekly shopping occasion with about 101 respondents strongly agreeing to this, this may be to because of tight schedule to prevent running out of some items before the next purchase is due. With the intention of planning ahead and actually focusing on the food shopping with the specific price range. The respondents don't prefer to do their food shopping on daily bases and could pay less attention to discount coupon as both had the least mean.

\begin{tabular}{|l|l|}
\hline Place & Mean(SD) \\
\hline Supermarket & $4.16(1.08)$ \\
\hline Retail small shops & $3.17(1.09)$ \\
\hline Wet market & $3.06(1.32)$ \\
\hline Night market & $3.01(1.21)$ \\
\hline Mini market & $2.83(1.06)$ \\
\hline Internet & $1.53(0.89)$ \\
\hline One weekly shopping occasion & $3.50(1.38)$ \\
\hline Several purchases in a week & $3.22(1.18)$ \\
\hline Daily food purchase & $2.65(1.38)$ \\
\hline purchase on immediate need & $3.31(1.27)$ \\
\hline Precise food purchase & $3.80(1.09)$ \\
\hline purchase based on discount & $2.67(1.33)$ \\
\hline Priced food purchase & $3.57(1.15)$ \\
\hline Purchase on household food need & $4.05(1.00)$ \\
\hline Purchase on prepared food list & $3.97(0.98)$ \\
\hline sticking to prepared list & $3.51(1.15)$ \\
\hline Purchase unintended food & $2.82(1.15)$ \\
\hline Purchase on expiring dates & $4.04(0.98)$ \\
\hline purchase (RM) per month of Meat/chicken & $3.81(1.12)$ \\
\hline Fish & $3.51(1.15)$ \\
\hline Rice/flour & $3.84(1.05)$ \\
\hline Potato & $2.73(1.20)$ \\
\hline Fruits or vegetables & $3.21(1.21)$ \\
\hline Pasta or bread & $2.22)$ \\
\hline
\end{tabular}

Table 2: Food shopping profile.

Respondents agreed to always checking what they have at home before doing their food shopping, with careful consideration to the expiring dates on their food stuff labels, bearing in mind not to purchase what they don't need and foods that would soon expire or go bad. The statistics on food purchase per month, showed meat/chicken and rice/flour to be on the higher purchase level with an average of 3.81 and 3.84 respectively this is more than $30 \mathrm{~kg}$ for most households as rice is a staple food and major source of energy for Malaysian households and potato and bread are on the least purchase level with an average of 2.73 and 2.68 respectively.

\section{Household food consumption and behavior towards leftover}

Table 3 indicates that the respondents plan their meal based on want they would want to eat rather than what they have in their house this could be a factor responsible for food wastage if the food are not properly stored and get long overdue, leading to guilty felt from food wasting. Most people when planning meals tend to take considerations in ways to preserve or use their leftover food however food still gets wasted in the household level especially during the festive periods even as people tend to avoid throwing away food. Respondents seek ways to preserve their left over by storing it properly in their refrigerator, heating and storing in cupboards to be eaten later or feeding to their pets of which [9]. Most people do not practice because they don't have pets. Respondent throw away lots of food from time to time but this survey focused on a one-week interval to avoid making respondents to think too much. The measure of food waste pattern is shown in Table 3.

\begin{tabular}{|l|l|}
\hline Food Waste & Mean (SD) \\
\hline Consume based on availability & $3.36(1.21)$ \\
\hline Emotional effect on leftover & $3.56(1.24)$ \\
\hline Usability of leftover food & $3.42(1.12)$ \\
\hline Wastage during festive seasons & $2.98(1.25)$ \\
\hline Immediate discarding of food & $2.45(1.28)$ \\
\hline Few hours discarding of food & $2.72(1.39)$ \\
\hline Usage of leftover food & $3.71(1.19)$ \\
\hline Storage and usage of leftover & $3.88(1.14)$ \\
\hline Don't have leftover food & $3.08(1.25)$ \\
\hline Left over fed to pets & $2.61(1.47)$ \\
\hline
\end{tabular}

Table 3: Household behavior and left-over pattern.

\section{Analysis on amount of household food wastage}

As shown in Table 4, which revealed how often people throw away food. Most of the samples agree to throwing away food on a weekly basis and within 3 to 5 days of food consumption, storage or purchase. The amount of food thrown away in $\mathrm{kg}$ is measured on the frequency of how much respondent estimated the amount to be, and majority of the households throw away very little amount of about 0 to $0.5 \mathrm{~kg}$ weekly which may not seem so much but accumulates with time, the amount of food thrown away in monetary value has a higher frequency at 1-5 ringgit, which is about 1 to $10 \mathrm{~kg}$ depending on the food.

\section{Reasons for household food wastage}

Table 5 shows the attitudes of people and factors that encourage people to throw away food, the data reveals the average number of people that get rid of food because it has expired, rotten, ruined cooking due to burnt or salty and food storage failure example freezer failure is the highest. While less people agreed to food being thrown away because respondent was eating out or forgot they had food and food not tasting nice at lowest average [9]. Huge food purchases or 
Citation: Fegalo K, Ismail TH (2017) Household Purchase and Generation of Food Waste in Malaysia (Sri Serdang and Taman Connaught Cheras Kuala Lumpur). Adv Recycling Waste Manag 2: 139. doi:10.4172/2475-7675.1000139

Page 5 of 8

improper management of food storage can lead to food spoilage, food getting expired, developing bad smell and taste, or being forgotten in the fridge, resulting in food being necessarily not suitable for consumption leaving only the option of getting rid of the food. Cooking more than required or serving more than can be consumed results in remnant, which are mostly discarded. Storing food under sub-optimal conditions, leading to lose in the quality of the food [9]. Not being careful about expiring dates or being too cautious about food hygiene and guidance on labeling, leads to throwing away food that has passed its best before use date even if it's still edible. Respondents not being satisfied with food taste and trying to avoid having the same food or meal frequently can be another reason for discarding edible food [9]. Households faced with the concerned and desire to shop, cook and prepare food with convenience and time constraints in mind. Stocking up on food was as a way of protecting themselves from the inconvenience of having to shopping frequently if an unplanned or unexpected event occurred, or simply trying to create a means of freeing up time for other responsibilities or personal pursuits and reducing future stress. However, stock piling perishable products as a way of reducing trips to the shops often will result in food going to waste [10].

\begin{tabular}{|c|c|c|c|c|c|}
\hline & \multirow[t]{2}{*}{ Mean (SD) } & \multicolumn{4}{|c|}{ Frequency $\%$} \\
\hline & & Daily & 01-Feb & 03-May & $>1$ week \\
\hline Raw or cooked meat or fish & $3.17(0.88)$ & 2.9 & 22.2 & 29.3 & 45 \\
\hline Raw or cooked fruits or vegetables & $3.06(0.89)$ & 2.9 & 28 & 28.9 & 40.2 \\
\hline Dairy products & $3.23(0.88)$ & 3.5 & 18.6 & 28.9 & 48.9 \\
\hline Rice, pasta/bread & $3.15(0.88)$ & 2.9 & 23.8 & 28.9 & 44.4 \\
\hline Restaurant food & $3.13(0.94)$ & 5.1 & 21.9 & 28.9 & 43.7 \\
\hline Drinks & $3.21(0.88)$ & 3.5 & 18.6 & 31.5 & 45.7 \\
\hline Refrigerated food & $3.30(0.82)$ & 1 & 19.3 & 28.9 & 50.2 \\
\hline Stored food in the cupboard & $3.31(0.81)$ & 1.3 & 17.4 & 30.9 & 49.2 \\
\hline Other kind of foods thrown away & $3.25(0.83)$ & 1.3 & 20.3 & 31.2 & 46.6 \\
\hline Amount of food thrown out in $\mathrm{kg}$ & & $<0.2$ & $0.2-0.5$ & $0.5-1$ & $>1$ \\
\hline Meat/chicken/fish & $1.84(0.91)$ & 43.4 & 35.4 & 16.4 & 4.8 \\
\hline Rice, pasta, potato/bread & $1.91(0.97)$ & 42.4 & 34.7 & 14.5 & 8 \\
\hline Amount of food thrown out in RM & & $<1$ & 01-May & 05-Oct & $>10$ \\
\hline Restaurant food & $2.23(1.22)$ & 30.2 & 37 & 21.5 & 11.3 \\
\hline Drinks & $2.15(1.36)$ & 33.4 & 42.8 & 13.8 & 6.4 \\
\hline Refrigerated food & $2.33(1.21)$ & 26 & 37.6 & 22.8 & 11.9 \\
\hline Other food thrown away & $2.29(1.18)$ & 25.7 & 41.8 & 19 & 13.3 \\
\hline
\end{tabular}

Table 4: Household food wastage pattern.

\begin{tabular}{|l|l|}
\hline Types of Food & Mean (SD) \\
\hline Expired food & $3.84(1.21)$ \\
\hline Not suitable condition & $3.28(1.21)$ \\
\hline Multi-purchased food & $3.02(1.11)$ \\
\hline Cooked too much/leftovers & $3.00(1.13)$ \\
\hline Eating out & $2.50(1.19)$ \\
\hline Forget about the food & $2.72(1.22)$ \\
\hline Food doesn't taste nice & $2.79(1.24)$ \\
\hline Mold or rotten food & $3.78(1.12)$ \\
\hline
\end{tabular}

\begin{tabular}{|l|l|}
\hline Ruined /burnt/salty over cooked & $3.70(1.07)$ \\
\hline Food accidents storage failure & $3.58(1.21)$ \\
\hline Inadequate storage place or space & $2.84(1.24)$ \\
\hline
\end{tabular}

Table 5: Reasons for throwing away food.

\section{Relationship between household demography and food wastage}

The independent sample t-test conducted (Table 6) compared if there was any evidence of food waste in both Serdang and Cheras, the table shows the analysis for the two locations when respondent were asked if they don't usually have left over food, with at sample size of 154 at Serdang $(\mathrm{M}=3.12, \mathrm{SD}=1.19)$ and Cheras with a sample size of 
$157(\mathrm{M}=3.04, \mathrm{SD}=1.31), \mathrm{t}(309)=0.598, \mathrm{p}=0.55$ (two tailed). Showing that there is no significant difference. The magnitude of the difference in the means (mean difference $=0.85,95 \%$ confidence interval -0.19 to 0.37 which was very small. however there was a significant difference in the score for waste generated in ringgit between Serdang and Cheras Kuala Lumpur (Serdang Mean $7.85=, \mathrm{SD}=3.09$ ) and (cheras Mean
$=12.12, \mathrm{SD}=5.09) ; \mathrm{t}(257.98)=-4.77$ with a mean difference of -2.27 , $95 \%$ confidence interval of -3.208 to -1.333 which is very large. Therefore, the wastage of food in Cheras area is more this could be as a result of larger purchase of food and the estimate that municipal and food waste generation increases with increase income countries [11].

\begin{tabular}{|l|l|l|l|l|l|l|l|l|}
\hline \multicolumn{2}{|l|}{ Levene's Test for Equality of Variances } & F & Sig. & T & Sig. & Mean & $\begin{array}{l}\text { Std. } \\
\text { different }\end{array}$ & \multicolumn{2}{|l|}{ Error } & $\begin{array}{l}\text { 95\% Confidence Interval of } \\
\text { the Difference }\end{array}$ & Lower & upper \\
\hline & & & & 2 tailed & difference & & -3.208 & -1.333 \\
\hline $\begin{array}{l}\text { Total amount of food } \\
\text { waste }\end{array}$ & 33.97 & 0 & -4.77 & 0 & -2.27 & 0.476 & & -0.195 \\
\hline $\begin{array}{l}\text { Don't have left over } \\
\text { food }\end{array}$ & 3.24 & 0.073 & 0.598 & 0.55 & 0.085 & 0.142 & 0.365 \\
\hline
\end{tabular}

Table 6: Independent sample test.

The linear regression analysis (Tables 7 and 8) showed the various factors that food wastage in the households at $p=0.05$, where income, house occupants, amount of food purchase, race and reasons for food wastage. All these factors have a positive correlation with total amount of food thrown away in kilogram which has a mean of $3.75 \mathrm{~kg}$ and a standard deviation of 1.80 for the 311 respondents at least per weekly basis [9]. As income, food purchase and type or number of house occupant increases, total food waste increases. With people being motivated to eat healthy, and providing abundant food for the household, thereby they strive to provide a healthy food for healthy lifestyle choices for their households as such they tend to purchase fresh products with shorter shelf life, than can be consumed in the household. This is another common factor that results in food wastage [9]. Irrespective of these factors there would be food wastage but the highest correlation is the reasons that influence throwing away food, food wastage also depends on the income and type of house occupants $[9,12]$. From the result 0.069 of the of these factor variances are explained by the analysis. The analysis of variance verifies the statistical signifance of the result at $\mathrm{p}$ value $0.001<0.05$. From the beta standard coefficients, amount of food purchase and reason for food wastage are the strongest unique contribution at 0.203 and 0.096 to defining or enhancing food wastage when the variance explained by all the other factors in the test are controlled. Income is the least contributing factor at -0.021 .

\begin{tabular}{|c|c|c|c|c|c|c|c|c|c|c|}
\hline \multirow[t]{4}{*}{ Model } & \multirow{4}{*}{$\begin{array}{l}\mathbf{R} \\
0.263\end{array}$} & \multirow{4}{*}{$\begin{array}{l}\text { R Square } \\
0.069\end{array}$} & \multirow{4}{*}{$\begin{array}{ll}\begin{array}{l}\text { Adjusted } \\
\text { Square }\end{array} & \mathbf{R} \\
0.054 & \end{array}$} & \multirow{4}{*}{$\begin{array}{l}\text { Std. Error of } \\
\text { the Estimate }\end{array}$} & \multirow{4}{*}{$\begin{array}{l}\mathbf{F} \\
4.454\end{array}$} & \multirow{4}{*}{$\begin{array}{l}\text { Sig } \\
0.001\end{array}$} & \multicolumn{2}{|c|}{ Sum of Squares } & \multirow{2}{*}{$\begin{array}{l}\text { df } \\
5\end{array}$} & \multirow{2}{*}{$\begin{array}{l}\text { Mean } \\
\text { Square }\end{array}$} \\
\hline & & & & & & & Regression & 68.59 & & \\
\hline & & & & & & & Residual & 924.07 & 300 & 3.080 \\
\hline & & & & & & & Total & 992.65 & 305 & \\
\hline & Race & Income & $\begin{array}{l}\text { House } \\
\text { occupants }\end{array}$ & Food Purchase & \multicolumn{6}{|c|}{ Reason for wastage } \\
\hline Pearson & 0.098 & 0.050 & 0.068 & 0.145 & \multicolumn{6}{|c|}{0.220} \\
\hline Sig. (1-tailed) & 0.043 & 0.190 & 0.117 & 0.005 & \multicolumn{6}{|c|}{0.000} \\
\hline
\end{tabular}

Table 7: Linear regression analysis on factors that influence food wastage.

\begin{tabular}{|c|c|c|c|c|c|}
\hline \multirow[t]{2}{*}{ Factors } & \multirow{2}{*}{$\begin{array}{l}\text { Standardized } \\
\text { Coefficients Beta }\end{array}$} & \multirow[t]{2}{*}{$\mathbf{t}$} & \multirow[t]{2}{*}{ Sig. } & \multicolumn{2}{|c|}{ 95.0\% Confidence Interval } \\
\hline & & & & Lower Bound & Upper Bound \\
\hline Food purchase & 0.096 & 1.488 & 0.138 & -0.409 & 2.144 \\
\hline House occupants & 0.064 & 0.953 & 0.341 & -0.011 & 0.078 \\
\hline income & -0.021 & -0.330 & 0.742 & -0.064 & 0.184 \\
\hline race & 0.075 & 1.238 & 0.217 & -0.282 & 0.201 \\
\hline
\end{tabular}




\begin{tabular}{|l|l|l|l|l|l|}
\hline $\begin{array}{l}\text { Reasons for } \\
\text { wastage }\end{array}$ & 0.203 & 3.607 & .000 & -0.079 & 0.348 \\
\hline
\end{tabular}

Table 8: Analysis on factors that influence food wastage.

Food wastage is influence by the type of household, as adult waste more food than children, also single occupant household tend to waste food based on their income level [2]. Although that lower income household spend majority of their income on food, also accessibility of food stores as those in Sri Serdang area had smaller number of food stores to purchase food and most food items are expensive compare to Cheras where the residents had variety of supermarket, night market and wet market to purchase more food at different prices resulting in more food wastage in Cheras than in Serdang. From this study residence also affect food waste, as respondent in Cheras tend to throw away more food the residents in Sri Serdang this could be due to the income and type of household occupants. Culture doesn't really determine the amount of food thrown away as income and type of household subdues the cultural demography of household and food wastage.

There is a huge difference among households in the amount of edible food wasted every day [9]. Importantly distinguishing between avoidable and unavoidable food waste would assist in creating a sustainable structure to address food waste in the household level. This would provide a focus on the extent to which food waste prevention is obtainable, thus providing strategies for food waste minimization. Avoidable food waste is the food thrown away because it is not wanted, or the food was allowed to get past its best [13]. The vast majority of avoidable food is composed of material that was, at some point prior to disposal, edible, even though a proportion is not edible at the time of disposal due to deterioration (e.g., gone moldy) [13].

Avoidable food waste includes foods or parts of food that are recognized as edible by the vast majority of people. Unavoidable food waste is described as waste from food that is not, and has not been, edible under normal circumstances [14]. This includes parts of foods such as fruit skin, apple cores and meat bones. Although this classification provides insight into the degree to which food waste prevention is feasible (i.e., there will always be an amount of food waste produced that is unavoidable) [15]. Although what is considered edible by 'a majority of people' depends on a number of factors, such as culture in the form of shared values and common practices, religious beliefs, social norms and personal preferences [16].

With household producing most of the food waste even larger other food sectors, therefore only these households have the potential to reduce food waste produce, which will go a long way in reduction of waste management in the generation aspect [9]. There is the need to consider the inedible portion of food waste, and the impacts associated with emissions and resources use rooted in the production of food that eventually ends up being wasted. The issue of inedible food waste is in line with the fact that this portion of the food waste stream in the household cannot be avoided [3]. Since inedible food waste by definition cannot be eaten. However, inedible food waste can still be used as an input into other processes, such as composting, bio-energy generation, or the production of animal feed; and therefore, has worth in its own right instead of being thrown out [3].

Food waste from linked embedded carbon products from previous life cycle stages is involved in carbon footprint, which results in a huge climate impact on the environment [12]. As food waste decaying at landfills produce methane gas which contributes $25 \%$ more to global warming than carbon dioxide which would be the primary end product if the wasted food had been eaten. Household food waste generated is one of the key components of solid waste, it also shows the waste of resources allocated to food economically and potential valuable food source or resources that can be used in other energy process as most edible food get wasted. Recycling food waste into animal feed and via composting and treatment of unavoidable food waste and recover energy through anaerobic digestion $[9,12,17]$.

\section{Conclusion}

Food wastage is a prominent concern in Malaysia as it increases the amount of solid waste generated, this study is evident of food wastage at the household level of consumer stage. Irrespective of the race or income, amount of person in the household and the type of household affect there would still be evidence of food wastage because not all food being purchased gets used up or eaten a small portion or a huge portion will still be thrown away depending on the household. Conserving food wastage at household level will go a long way to improve the waste management process in Malaysia and increase the usefulness of resource being allocated to food supply and food produced. Also curtailing food waste and avoiding surplus food generation during consumption would increase sustainability and health to the general population in Malaysia thus reducing the stress placed on environmental issues as regards to the final disposal cost of the food waste and municipal solid waste management.

\section{References}

1. Griffin M, Sobal J, Lyson TA (2009) An analysis of a community food waste stream. Agricult Human Values 26: 67-81.

2. Parfitt J, Barthel M, Macnaughton S (2010) Food waste within food supply chains: quantification and potential for change to 2050. Philosophical Transactions of the Royal Society of London B: Biol Sci 365: 3065-3081.

3. Nahman A, de Lange W (2013) Costs of food waste along the value chain: Evidence from South Africa. Waste Manag 33: 2493-2500.

4. Tarmudi Z, Abdullah ML, Tap M, Osman A (2009) An overview of municipal solid wastes generation in Malaysia. J Technol 51: 1-5.

5. Ricardo S, Joanna K, Mernies J (2006) Estimating Household and Institutional Food Wastage and Losses in the context of measuring food. Food and Agriculture organization of The United Nations.

6. Gustavsson J, Cederberg C, Sonesson U, Van Otterdijk R, Meybeck A (2011) Global food losses and food waste. Rome-FAO.

7. Baker D, Fear J, Denniss R (2009) What A Waste an Analysis Of Household Expenditure On Food.

8. Hassan SH, Ahzahar N, Fauzi MA, Eman J (2012) Waste management issues in the Northern Region of Malaysia. Procedia-Social Behav Sci 42: 175-181.

9. Koivupuro HK, Hartikainen H, Silvennoinen K, Katajajuuri JM, Heikintalo N, et al. (2012) Influence of sociodemographical, behavioural and attitudinal factors on the amount of avoidable food waste generated in Finnish households. Intern J Cons Studies 36: 183-191. 
Citation: Fegalo K, Ismail TH (2017) Household Purchase and Generation of Food Waste in Malaysia (Sri Serdang and Taman Connaught Cheras Kuala Lumpur). Adv Recycling Waste Manag 2: 139. doi:10.4172/2475-7675.1000139

Page 8 of 8

10. Graham-Rowe E, Jessop DC, Sparks P (2014) Identifying motivations and barriers to minimising household food waste. Resour, Conserv Recyc 84: 15-23.

11. Iacovidou E, Ohandja DG, Gronow J, Voulvoulis N (2012) The household use of food waste disposal units as a waste management option: A review. Crit Rev Environ Sci Technol 42: 1485-508.

12. Silvennoinen K, Katajajuuri JM, Hartikainen H, Jalkanen L, Koivupuro HK, et al. (2012) Food waste volume and composition in the Finnish supply chain: special focus on food service sector. Proceedings Venice.

13. Papargyropoulou E, Lozano R, Steinberger JK, Wright N, Bin Ujang Z (2014) The food waste hierarchy as a framework for the management of food surplus and food waste. J Clean Prod 76: 106-115.
14. Zainal Badari SA, Arcot J, Haron SA, Paim L, Sulaiman N, et al. (2012) Food variety and dietary diversity scores to understand the food-intake pattern among selected Malaysian households. Ecol Food Nutri 51: 265-299.

15. Cooper EE (2013) Evaluating household food insecurity: applications and insights from rural Malaysia. Ecol Food Nutrit 52: 294-316.

16. Refsgaard K, Magnussen K (2009) Household behaviour and attitudes with respect to recycling food waste-experiences from focus groups. J Environ Manag 90: 760-771.

17. Hall KD, Guo J, Dore M, Chow CC (2009) The progressive increase of food waste in America and its environmental impact. PloS one 4: e7940. 